\title{
ASSOCIATION BETWEEN BODY MASS INDEX (BMI), BODY FAT PERCENTAGE AND PULMONARY FUNCTIONS IN OBESE, OVERWEIGHT AND NORMAL WEIGHT ADOLESCENTS
}

\author{
Sanhita Mukherjee1, Diptakanti Mukhopadhyay²
}

${ }_{1}^{1}$ Associate Professor, Department of Physiology, Calcutta National Medical College, Kolkata, West Bengal, India.

${ }^{2}$ Associate Professor, Department of Community Medicine, College of Medicine and Sagar Dutta Hospital, Kolkata, West Bengal, India.

\section{ABSTRACT}

\section{BACKGROUND}

Abdominal obesity may influence the lung function through a mechanism that restricts descent of diaphragm and limits lung expansion compared to overall adiposity, which may compress the chest wall. Multiple measures of adiposity showed significant inverse relationship with both spirometry and static lung volumes. However, only a few studies have considered the associations between body fat distribution, body composition and lung function in young adults.

The aim of the study was to find out whether there was any correlation between the Body Mass Index, Body Fat Percentage and FVC, $\mathrm{FEV}_{1}$ and $\mathrm{FEF}_{25-75}$ in underweight, normal weight and overweight adolescents.

\section{MATERIALS AND METHODS}

158 students consisting of 90 boys and 68 girls in the age group of 18 to 19 years were included in the study. They were classified into underweight, normal weight and overweight groups according to WHO guidelines. The body fat percentage was measured by using Harpenden skinfold caliper and FVC, $\mathrm{FEV}_{1}$ and $\mathrm{FEF}_{25-75}$ were assessed by using RMS Helios 702 electronic spirometer.

\section{RESULTS}

The $\mathrm{FEF}_{25-75}$ values were low in the overweight than in the normal weight subjects. FVC, $\mathrm{FEV}_{1}$ and $\mathrm{FEF}_{25-75}$ had a negative correlation with BMI and the body fat percentage in males. The underweight males had a positive significant correlation between $\mathrm{BMI}$, body fat percentage and $\mathrm{FVC}, \mathrm{FEV}_{1}$ and $\mathrm{FEF}_{25-75}$. In females, only $\mathrm{FEF}_{25-75}$ had a significant correlation with $\mathrm{BMI}$ and the body fat percentage.

\section{CONCLUSION}

There was a significant difference in the $\mathrm{FVC}, \mathrm{FEV}_{1}$ and the $\mathrm{FEF}_{25-75}$ values between the underweight, normal weight and the overweight subjects. Body fat percentage had a stronger correlation than BMI.

\section{KEY WORDS}

PFT, BMI, Body Fat Percent.

HOW TO CITE THIS ARTICLE: Mukherjee S, Mukhopadhyay D. Association between Body Mass Index (BMI), body fat percentage and pulmonary functions in obese, overweight and normal weight adolescents. J. Evolution Med. Dent. Sci. 2018;7(44):4789-4793, DOI: $10.14260 /$ jemds/2018/1068

\section{BACKGROUND}

There is an increased prevalence of obesity around the world. ${ }^{1}$ Indo-Asian countries are now facing the unique challenge of a rapid rise in childhood obesity despite a constant burden of undernutrition. ${ }^{2}$ Obesity has been associated with many health hazards because of its strong connection with several metabolic complications like dyslipidaemia, diabetes mellitus, hypertension and cardiovascular accidents. Obesity has a clear potential to have a direct effect on respiratory well-being 3 as well. Several previous studies have examined the relations between obesity and lung function and they used Body Mass Index (BMI) as a measure of overall adiposity. ${ }^{3,4,5}$ However, BMI does not give indication of fat distribution and body fat composition.6,7 Abdominal obesity, also known as central

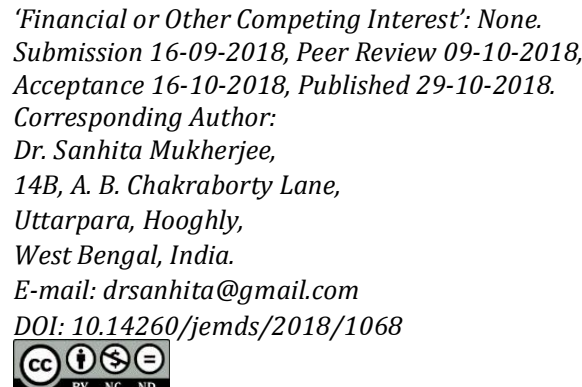

obesity, occurs when excessive abdominal fat around the stomach and abdomen has built up that leads to a mass load of adipose tissue around the rib cage and abdomen and in the visceral cavity. ${ }^{3}$ It may influence the lung function through a mechanism that restrict descent of diaphragm and limit lung expansion compared to overall adiposity which may compress the chest wall.

There are many abdominal adiposity markers like WaistHip Ratio (WHR), Waist Circumference (WC), Waist-to-Height Ratio (WHtR). Among them WHtR has the greatest accuracy in prediction of central adiposity. ${ }^{8}$ Multiple measures of adiposity showed a significant inverse relationship with both spirometry and static lung volumes. ${ }^{9}$ However, only a few studies have considered the associations between body fat distribution, body composition and lung function in young adults.

The aim of the present study was to analyse the relation between BMI, body fat distribution (WC, WHtR) and body composition (percentage of body fat) and the lung function (FVC, $\mathrm{FEV}_{1}$ and $\mathrm{FEF}_{25-75}$ ) in young adults in our population.

\section{MATERIALS AND METHODS}

This cross-sectional study was performed on 158 healthy, otherwise asymptomatic young individuals ( 90 boys and 68 girls) among age group of 18 - 19 years selected from medical students. Individuals doing regular exercise, having 
respiratory infections or any other respiratory diseases, smokers, hypertensive or having any musculoskeletal deformities of chest/ vertebral column were excluded from the study.

The subjects to be enrolled for the study were informed about the study and procedure details and an informed consent was obtained. The subjects were all healthy, asymptomatic. Students between 18 - 19 years with a BMI $<30$ and with no h/o smoking and alcoholism were included.

All participants provided information on age, family history, personal habits (alcohol intake, tobacco consumption, type and level of physical exercise, drug ingestion, known pathological conditions). A detailed physical examination was conducted to exclude cardiac or pulmonary diseases. The study was approved by Institutional Ethical Committee.

All the records i.e. anthropometric measurements, skin fold measurements and recording of pulmonary function tests were conducted in one sitting on the same day. Anthropometric variables like height and weight were obtained. Height was measured to the nearest of $0.1 \mathrm{~cm}$ and weight was measured to the nearest of $0.1 \mathrm{~kg}$ with minimum of clothes and no shoes. Body mass index was calculated by Quetelet's Index.10

The waist circumference $(\mathrm{cm})$ was measured at a point midway between the lower rib and iliac crest in a horizontal plane. The hip circumference $(\mathrm{cm})$ was measured at the widest girth of the hip. The measurements were recorded to the nearest $0.1 \mathrm{~cm}$. Skin fold thickness was measured at four standard anatomical sites with the help by measuring skin fold thickness at four sites (4 SFT-biceps, triceps, subscapular and suprailiac) with the help of Harpenden's caliper. To calculate percentage of body fat linear regression equations of Durnin and Womersley was used.11

Lung function was assessed by using RMS Helios 702 electronic spirometer. The essential parameters obtained were FVC, $\mathrm{FEV}_{1}$ and $\mathrm{FEF}_{25-75}$. The forced expiratory volume in one second $\left(\mathrm{FEV}_{1}\right)$ and the forced expiratory flow between $25 \%$ and $75 \%$ of vital capacity $\left(\mathrm{FEF}_{25-75}\right)$ that reflects small airway patency are objective measures of airway obstruction. ${ }^{12}$ These tests were recorded at noon before lunch, as expiratory flow rates are highest at noon. For each volunteer three satisfactory efforts were recorded according to the norms given by American Thoracic Society. ${ }^{13}$

158 subjects ( 90 boys and 68 girls) were classified into normal weight and overweight groups according to WHO guidelines. ${ }^{14}$ Unpaired t-test was performed to see the differences in lung function test parameters among these two groups, both in boys and girls. Statistical significance was indicated by ' $\mathrm{P}$ ' value $<0.05$.

Correlation of ventilatory lung function tests with BMI, body fat percentage, WC and WtHR were noted by using Pearson's correlation coefficient test. The non-zero values of ' $r$ ' between -1 to 0 indicate negative correlation.

\section{RESULTS}

Table 1 shows comparison of Mean \pm SD values of anthropometric parameters of control and obese group.

Table 2 and 3 shows there is significant differences in $\mathrm{FVC}, \mathrm{FEV}_{1}$ and $\mathrm{FEF}_{25-75}$ values in obese and control groups both for boys and girls.

Table 4 shows significant negative correlation of BMI with $\mathrm{FEF}_{25-75}$ in boys. Although, $\mathrm{FVC}$ and $\mathrm{FEV}_{1}$ are also negatively correlated with BMI that correlation is not significant. Body fat percent in boys has significant exponential relationship with FVC and $\mathrm{FEF}_{25-75}$. The measure of central obesity, i.e. WC and WtHR both have significant negative correlation with all three lung function parameters FVC, FEV $_{1}$ and $\mathrm{FEF}_{25-75}$ in case of boys.

Table 5 shows in case of girls BMI, BF\%, WC and WtHR all have significant negative relationship with $\mathrm{FVC}, \mathrm{FEV}_{1}$ and $\mathrm{FEF}_{25-75}$

\begin{tabular}{|c|c|c|c|c|c|c|c|c|}
\hline & \multicolumn{4}{|c|}{$\begin{array}{c}\text { Normal Weight (BMI } 18.5-24.9 \mathrm{~kg} / \mathrm{m} 2) \\
\text { Mean } \pm \text { SD }(n=57)\end{array}$} & \multicolumn{4}{|c|}{$\begin{array}{c}\text { Obese-Overweight (BMI 25-30 kg/m2) } \\
\text { Mean } \pm \text { SD }(n=33)\end{array}$} \\
\hline Boys & BMI (kg/m2) & Body Fat \% & WC (cm) & WtHR & BMI (kg/m2) & Body Fat \% & WC (cm) & WtHR \\
\hline & $21.69 \pm 1.84$ & $16.96 \pm 5.25$ & $31.91 \pm 2.44$ & $0.19 \pm 0.01$ & $29.22 \pm 3.09$ & $23.3 \pm 3.71$ & $40.13 \pm 3.89$ & $0.24 \pm 0.026$ \\
\hline & \multicolumn{4}{|c|}{$\begin{array}{c}\text { Normal Weight (BMI 18.5-24.9 kg/m2) } \\
\text { Mean } \pm \text { SD }(n=44)\end{array}$} & \multicolumn{4}{|c|}{$\begin{array}{c}\text { Obese-Overweight (BMI 25-30 kg/m2) } \\
\text { Mean } \pm \text { SD }(\mathrm{n}=24)\end{array}$} \\
\hline Girls & BMI (kg/m2) & Body Fat \% & $W C(\mathbf{c m})$ & WtHR & BMI (kg/m2) & Body Fat \% & WC (cm) & WtHR \\
\hline & $22.17 \pm 1.8$ & $25.54 \pm 2.2$ & $33.06 \pm 2.58$ & $0.21 \pm 0.015$ & $28.2 \pm 2.81$ & $32.78 \pm 3.42$ & $36.09 \pm 3.22$ & $0.23 \pm 0.026$ \\
\hline
\end{tabular}

\begin{tabular}{|c|c|c|c|c|c|c|c|c|}
\hline & BMI Category & $\mathbf{n}$ & Mean \pm SD & $\begin{array}{r}\text { Leve } \\
\text { Equalit }\end{array}$ & $\begin{array}{l}\text { est for } \\
\text { ariances }\end{array}$ & & & \\
\hline \multirow{2}{*}{ FVC (L) } & Normal BMI & 57 & $3.34 \pm .494$ & $\mathrm{~F}$ & Sig & $\mathrm{t}$ & $\mathrm{df}$ & Sig. (2-Tailed) \\
\hline & Overwt-Obese & 33 & $3.09 \pm .415$ & 1.969 & .164 & 2.377 & 88 & $.020^{*}$ \\
\hline \multirow{2}{*}{$\mathrm{FEV}_{1}(\mathrm{~L})$} & Normal BMI & 57 & $3.02 \pm .518$ & \multirow{2}{*}{.061} & \multirow{2}{*}{.806} & \multirow{2}{*}{3.005} & \multirow{2}{*}{88} & \multirow{2}{*}{$.003^{*}$} \\
\hline & Overwt-Obese & 33 & $2.68 \pm .508$ & & & & & \\
\hline \multirow{2}{*}{$\mathrm{FEF}_{25-75}(\mathrm{~L} / \mathrm{S})$} & Normal BMI & 57 & $4.11 \pm .951$ & \multirow[b]{2}{*}{.083} & \multirow[b]{2}{*}{.774} & \multirow[b]{2}{*}{4.738} & \multirow[b]{2}{*}{88} & \multirow[b]{2}{*}{$.000^{*}$} \\
\hline & Overwt-Obese & 33 & $3.15 \pm .889$ & & & & & \\
\hline
\end{tabular}




\begin{tabular}{|c|c|c|c|c|c|c|c|c|}
\hline & BMI Category & $\mathbf{n}$ & Mean \pm SD & $\begin{array}{r}\text { Levene's Te } \\
\text { of Va }\end{array}$ & quality & & & \\
\hline \multirow[t]{2}{*}{ FVC (L) } & Normal BMI & 44 & $2.4618 \pm 0.275$ & $\mathrm{~F}$ & Sig & $\mathrm{t}$ & $\mathrm{df}$ & $\begin{array}{c}\text { Sig. } \\
\text { (2-Tailed) }\end{array}$ \\
\hline & Over Weight-Obese & 24 & $2.2104 \pm 0.306$ & .142 & .707 & 3.458 & 66 & $.001^{*}$ \\
\hline \multirow{2}{*}{$\mathrm{FEV}_{1}(\mathrm{~L})$} & Normal BMI & 44 & $2.1634 \pm 0.297$ & \multirow{2}{*}{1.623} & \multirow{2}{*}{.207} & \multirow{2}{*}{3.213} & \multirow{2}{*}{66} & \multirow{2}{*}{$.002^{*}$} \\
\hline & Over Weight-Obese & 24 & $1.9212 \pm 0.295$ & & & & & \\
\hline \multirow{2}{*}{$\mathrm{FEF}_{25-75}(\mathrm{~L} / \mathrm{S})$} & Normal BMI & 44 & $2.8048 \pm 0.568$ & \multirow{2}{*}{1.440} & \multirow{2}{*}{.234} & \multirow{2}{*}{2.759} & \multirow{2}{*}{66} & \multirow{2}{*}{$.008^{*}$} \\
\hline & Over Weight-Obese & 24 & $2.4246 \pm 0.493$ & & & & & \\
\hline \multicolumn{9}{|c|}{ Table 3. FVC, FEV $V_{1}$ and FEF $F_{25-75}$ values in Overweight, Obese and Control Groups in Girls } \\
\hline
\end{tabular}

\begin{tabular}{|c|c|c|c|c|}
\hline \multicolumn{5}{|c|}{ Correlations } \\
\hline & & FVC (L) & FEV $_{1}(\mathrm{~L})$ & $\mathrm{FEF}_{25-75}(\mathrm{~L} / \mathrm{S})$ \\
\hline \multirow{2}{*}{ BMI } & Pearson Correlation & $-.236^{*}$ & $-.223^{*}$ & $-.341^{* *}$ \\
\hline & Sig. (2-Tailed) & .025 & .034 & .001 \\
\hline \multirow{2}{*}{ Body Fat Percentage } & Pearson Correlation & $-.217^{*}$ & -.198 & $-.317^{* *}$ \\
\hline & Sig. (2-Tailed) & .040 & .062 & .002 \\
\hline \multirow{2}{*}{ WC_cm } & Pearson Correlation & $-.289^{*}$ & $-.287^{*}$ & $-.364^{* *}$ \\
\hline & Sig. (2-Tailed) & .040 & .041 & .009 \\
\hline \multirow{2}{*}{ WHtR } & Pearson Correlation & $-.376^{* *}$ & $-.368^{* *}$ & $-.393^{* *}$ \\
\hline & Sig. (2-Tailed) & .007 & .008 & .004 \\
\hline
\end{tabular}

\begin{tabular}{|c|c|c|c|c|}
\hline \multicolumn{5}{|c|}{ Correlations } \\
\hline & & FVC (L) & FEV $_{1}(\mathrm{~L})$ & FEF $_{25-75}(\mathrm{~L} / \mathrm{S})$ \\
\hline \multirow{2}{*}{ BMI } & Pearson Correlation & $-.348^{* *}$ & $-.373^{* *}$ & $-.460^{* *}$ \\
\hline & Sig. (2-Tailed) & .004 & .002 & .000 \\
\hline \multirow{2}{*}{ Body Fat Percentage } & Pearson Correlation & $-.354^{* *}$ & $-.380^{* *}$ & $-.458^{* *}$ \\
\hline & Sig. (2-Tailed) & .003 & .001 & .000 \\
\hline \multirow{2}{*}{ WC_cm } & Pearson Correlation & $-.378^{*}$ & $-.353^{*}$ & $-.326^{*}$ \\
\hline & Sig. (2-Tailed) & .019 & .030 & .046 \\
\hline \multirow{2}{*}{ WHtR } & Pearson Correlation & $-.400^{*}$ & $-.336^{*}$ & -.305 \\
\hline & Sig. (2-Tailed) & .013 & .039 & .063 \\
\hline \multicolumn{5}{|c|}{ elation between BMI, Body Fat \%, WC, WHtR with FVC, FEV ${ }_{1}, F_{25-75}$ in Girls } \\
\hline
\end{tabular}

\section{DISCUSSION}

The present population based cross-sectional study showed significant differences in $\mathrm{FVC}, \mathrm{FEV}_{1}$ and $\mathrm{FEF}_{25-75}$ values in overweight, obese and control groups both for boys and girls. A significant inverse association of BMI- $\mathrm{FEF}_{25-75}$, BF\%- FVC and $\mathrm{FEF}_{25-75}, \mathrm{WHtR}$ and waist circumference with all pulmonary function was found in boys. In case of girls BMI, $\mathrm{BF} \%$, WC and $\mathrm{WtHR}$ all have significant negative relationship with FVC, FEV 1 and $\mathrm{FEF}_{25-75}$. The abdominal adiposity markers (WHtR and waist circumference) have strong negative association with $\mathrm{FEV}_{1}, \mathrm{FVC}$ and $\mathrm{FEF}_{25-75}$ and have better explanatory power than total body adiposity measures such as BMI according to the p-value significance and the coefficient values.

The results are consistent with finding of Scottish crosssectional survey of men and women aged $25-64$ yrs., by Chen et al where WC was inversely associated with FVC and $\mathrm{FEV}_{1}$ in both men and women.

In contrast to our finding, Lazarus et al found no inverse associations of waist circumference and waist/ hip ratio with FVC in women. ${ }^{15}$ Canoy et al showed WC had an inverse association that remained significant after adjustment for BMI only in females. ${ }^{16}$ Harik-Khan et al ${ }^{17}$ investigated the association of fat distribution and pulmonary function using waist/ hip ratio and reported an inverse association of $\mathrm{FEV}_{1}$ and waist/ hip ratio in men only. In our study, all adiposity markers have significant negative associations with pulmonary functions in females, whereas in males the measure of central obesity i.e. WC and WtHR both have significant negative correlation with all three lung function parameters FVC, $\mathrm{FEV}_{1}$ and $\mathrm{FEF}_{25-75}$ in case of boys. Although, $\mathrm{FVC}$ and $\mathrm{FEV}_{1}$ are also negatively correlated with BMI in boys that correlation is not significant.

Koziel et al in their study on 40 - 50 years of volunteers found no association of WHR (Waist-Hip Ratio) with FVC and $\mathrm{FEV}_{1}$ in females; however, in males FVC was negatively associated with WHR and positively with BMI and $\mathrm{FEV}_{1}$ was positively associated with BMI and WHR.18 Sorani et al demonstrated no significant effect of BMI on $\mathrm{FEV}_{1} / \mathrm{FVC}$ ratio

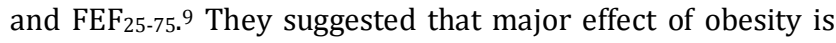
on lung volumes with no direct effect on airway obstruction.

But in our study FVC, $\mathrm{FEV}_{1}, \mathrm{FFF}_{25-75}$ all are negatively associated with adiposity markers in females. This intriguing sex difference in our finding can be explained by the difference in the proportion of fat and lean mass and the difference in the fat mass distribution between men and women. ${ }^{19}$ Although, the total body adiposity measures like BMI may have different effect on pulmonary functions in different gender or age group of people,15,16,17,20 but the central adiposity markers show consistent exponential relationship with lung volumes and airway obstruction.9,18 In our study also central or abdominal adiposity markers (WHtR 
and waist circumference) showed significant negative association with pulmonary function in both the sexes.

The major strength of our study lies as we used WHtR (Waist-to-Height ratio) as the central adiposity marker, as recent reports ${ }^{21}$ suggest WHtR is the better predictor for abdominal fat distribution. WHtR shows strong negative association with $\mathrm{FEV}_{1}, \mathrm{FVC}$ and $\mathrm{FEF}_{25-75}$ according to the pvalue significance and the coefficient values in our study.

The possible mechanism for the association of abdominal adiposity and pulmonary function is a mechanical limitation of chest expansion during the FVC manoeuvre. Increased abdominal mass may impede the descent of the diaphragm and increase thoracic pressure. ${ }^{22}$ Abdominal adiposity is likely to reduce expiratory reserve volume via compressing the lungs and diaphragm ${ }^{23,24}$ that will result in lower FVC measurements.

The reason of reduced $\mathrm{FEV}_{1}, \mathrm{FEF}_{25-75}$ or airway obstruction in central obesity may be due to the fact that visceral adipose tissue influences circulating concentrations of interleukin ${ }^{25}$ and cytokines that may act via systemic inflammation to negatively affect pulmonary function. ${ }^{26,27}$ Other investigators have reported an inverse association of serum leptin concentration with $\mathrm{FEV}_{1}$ as well as with higher levels of C-reactive protein, leukocytes and fibrinogens, which are other markers of systemic inflammation. ${ }^{28}$

In our study, no participant was a diagnosed asthmatic. $\mathrm{FEF}_{25-75}$ is an indicator of the mid expiratory flow rate and so it was taken as a marker for obstructive lung diseases like asthma and COPD. We found a significant difference across the BMI ranges with the lowest mean values in overweight males and females thus suggesting that they were prone to develop obstructive lung disease. This is in agreement with the study done by El Helaly et al. They further recommended that weight reduction would lead to a better asthma control.

The limitation of the present study was in its design. This was a cross-sectional study, which was carried out in a small group in a single institute. A longitudinal multicentric study in a larger population is needed.

\section{CONCLUSION}

The present study showed significant differences in FVC, $\mathrm{FEV}_{1}$ and $\mathrm{FEF}_{25-75}$ values in overweight, obese and control groups both for boys and girls. The measure of central obesity, i.e. WC and WtHR both have significant negative correlation with all three lung function parameters FVC, FEV and $\mathrm{FEF}_{25-75}$ in boys and girls. Our findings suggest that there is significant impairment of the pulmonary functions in the overweight young adult populations and that the possibility of small airway disease is higher in the overweight group.

\section{REFERENCES}

[1] WHO. Obesity: preventing and managing the global epidemic: report of a WHO consultation. WHO technical report series: 894. Geneva: The Office of Publication, World Health Organisation, 1999.

[2] Jafar TH, Qadri Z, Islam M, et al. Rise in childhood obesity with persistently high rates of under nutrition among urban school aged Indo-Asian children. Arch Dis Child 2008;93(5):373-8.

[3] Salome CM, King GG, Berend N. Physiology of obesity and effects on lung function. J Appl Physiol 2010;108(1):206-11.
[4] Maiolo C, Mohamed EI, Carbonelli MG. Body composition and respiratory function. Acta Diabetol 2003; 40 (Suppl 1):S32-S8.

[5] Lazarus R, Gore CJ, Booth M, et al. Effects of body composition and fat distribution on ventilatory function in adults. Am J Clin Nutr 1998;68(1):35-41.

[6] Wannamethee SG, Shaper AG, Whincup PH. Body fat distribution, body composition and respiratory function in elderly men. Am J Clin Nutr 2005;82(5):996-1003.

[7] Saxena Y, Sidhwani G, Upmanyu R. Abdominal obesity and pulmonary functions in young Indian adults: a prospective study. Indian J Physiol Pharmacol 2009;53(4):318-26.

[8] Vieira SA, Ribeiroa AQ, Hermsdorff HHM, et al. Waistto-height ratio index or the prediction of overweight in children. Rev Paul Pediatr 2018;36(1):52-8.

[9] Sorani A, Savalia C, Chavda B, et al. Analysis of lung functions in obese young adult male. International Journal of Basic and Applied Physiology. IJBAP 2009;2(1).

[10] Garrow JS, Webster J. Quetelet's index as a measure of fatness. Int J Obes 1985;9(2):147-53.

[11] Durnin JV, Womersley J. Body fat assessed from the body density and its estimation from skinfold thickness: measurements on 481 men and women aged 16 to 72 years. Br J Nutr 1974;32(1):77-97.

[12] Rao DR, Gaffin JM, Baxi SN, et al. The utility of forced expiratory flow between $25 \%$ and $75 \%$ of vital capacity in predicting childhood asthma morbidity and severity. J Asthma 2012;49(6):586-92.

[13] American Thoracic Society. Standardization of spirometry, 1994 Update. Am J Respir \& Crit Care Med 1995;152(3):1107-36.

[14] Chen Y, Rennie D, Cormier YF, et al. Waist circumference is associated with pulmonary function in normal-weight, overweight and obese subjects. Am J Clin Nutr 2007;85(1):35-9.

[15] Canoy D, Luben R, Welch A, et al. Abdominal obesity and respiratory function in men and women in the EPIC-Norfolk study, United Kingdom. Am J Epidemiol 2004;159(12):1140-9.

[16] Harik-Khan RI, Wise RA, Fleg JL. The effect of gender on the relationship between body fat distribution and lung function. J Clin Epidemiol 2001;54(4):399-406.

[17] Koziel S, Ulijaszek SJ, Szklarska A, et al. The effects of fatness and fat distribution on respiratory functions. Annals of Human Biology 2007;34(1):123-31.

[18] Bjorntorp P. Abdominal fat distribution and disease: an overview of epidemiological data. Ann Med 1992;24(1):15-8.

[19] Sgariboldi D, Faria FA, Carbinatto JC, et al. Influence of body mass index and age on the lung function of obese women. Rev Bras de Geriatr e Gerontol 2016;19(4):635-41.

[20] Wu HY, Xu SY, Chen LL, et al. Waist to height ratio as a predictor of abdominal fat distribution in men. Chinese Journal of Physiology 2009;52(6):441-5.

[21] Sugerman H, Windsor A, Bessos $M$, et al. Intraabdominal pressure, sagittal abdominal diameter and obesity comorbidity. J Intern Med 1997;241(1):71-9. 
[22] Ray CS, Sue DY, Bray G, et al. Effects of respiratory function. Am Rev Respir Dis 1983;128(3):501-6.

[23] Koenig SM. Pulmonary complications of obesity. Am J Med Sci 2001;321(4):249-79.

[24] Staiger H, Tschritter 0, Machann J, et al. Relationship of serum adiponectin and leptin concentrations with body fat distribution in humans. Obes Res 2003;11(3):368-72.

[25] Kern PA, Ranganathan S, Li C, et al. Adipose tissue tumor necrosis factor and interleukin- 6 expression in human obesity and insulin resistance. Am J Physiol Endocrinol Metab 2001;280(5):E745-E51.
[26] Gasteyger C, Tremblay A. Metabolic impact of body fat distribution. J Endocrinol Invest 2002;25(10):876-83.

[27] Sin DD, Man SF. Impaired lung function and serum leptin in men and women with normal body weight: a population based study. Thorax 2003;58(8):695-8.

[28] Ochs-Balcom HM, Grant BJ, Muti P, et al. Pulmonary functions and abdominal adiposity in the general population. Chest 2006;129(4):853-62. 